\title{
Unable to Position Lead Due to Coronary Sinus Dissection
}

National Cancer Institute

\section{Source}

National Cancer Institute. Unable to Position Lead Due to Coronary Sinus Dissection. NCI

Thesaurus. Code C100028.

The coronary sinus / left ventricular lead was not implanted because the coronary sinus

was dissected. (ACC) 